\title{
LIE SYMMETRY ANALYSIS TO GENERAL TIME-FRACTIONAL KORTEWEG-DE VRIES EQUATIONS
}

\author{
YOUWEI ZHANG
}

Abstract. In present paper, two class of the general time-fractional Korteweg-de Vries equations $(\mathrm{KdVs})$ are considered, a systematic investigation to derive Lie point symmetries of the equations are presented and compared. Each of them has been transformed into a nonlinear ordinary differential equation with a new independent variable are investigated. The derivative corresponding to time-fractional in the reduced formula is known as the Erdélyi-Kober fractional derivative.

Mathematics subject classification (2010): 26A33, 35K55.

Keywords and phrases: Time-fractional KdVs, Erdélyi-Kober operators, Lie symmetry analysis, RiemannLiouville fractional calculus.

\section{REFERENCES}

[1] E. S. Benilov, R. Grimshaw, E. P. Kuznetsova, The generation of radiating waves in a singularly-perturbed Koreteweg-de Vries equation, Phys. D 69 (1993) 270-278.

[2] D. A. Benson, M. M. Meerschaert, J. Revielle, Fractional calculus in hydrologic modeling: A numerical perspective, Water Reso. Res. 51 (2013) 479-497.

[3] G. W. Bluman, S. Anco, Symmetry and Integration Methods for Differential Equations, SpringerVerlag, Heidelburg, 2002.

[4] E. BUCKWAR, Y. LUCHKO, Invariance of a partial differential equation of fractional order under the Lie group of scaling transformations, J. Math. Anal. Appl. 227 (1998) 81-97.

[5] B. Cohen, J. Krommes, W. Tang, M. Rosenbluth, Nonlinear saturation of the dissipative trapped-ion mode by mode coupling, Nucl. Fus. 16 (1976) 971-992.

[6] K. Diethelm, The Analysis of Fractional Differential Equations, Lect. notes Math., Springer-Verlag, Berlin, 2010.

[7] V. D. Djordjevic, T. M. Atanackovic, Similarity solutions to nonlinear heat conduction and Burgers/Korteweg-deVries fractional equations, J. Comp. Appl. Math. 212 (2008) 701-714.

[8] R. K. GaZizov, A. A. KAS ATKIN, S. Y. LUKASHChUK, Continuous transformation groups of fractional differential equations (in Russian), Vestnik USATU 9 (2007) 125-135.

[9] R. K. Gazizov, A. A. Kas ATKIn, S. Y. LuKASHChuK, Symmetry properties of fractional diffusion equations, Phys. Scr. T136 (2009) 014016.

[10] R. Gorenflo, F. Mainardi, E. SCAlas, M. Raberto, Fractional calculus and continuous-time finance, III, The diffusion limit. Mathematical finance (Konstanz, 2000), Trends Math., (2001) 171180.

[11] M. ITо, An extension of nonlinear evolution equations of the $K d V(m K d V)$ type to higher orders, J. Phys. Soc. Japan 49 (1980) 771-778.

[12] M. ITO, A reduce program for finding symmetries of nonlinear evolution equations with uniform rank, Comp. Phys. Comm. 42 (3) (1986) 351-357.

[13] H. LIU, J. LI, Lie symmetry analysis and exact solutions for the extended $m K d V$ equation, Acta Appl. Math. 109 (2010) 1107-1119.

[14] H. LiU, J. LI, L. LiU, Lie symmetry analysis, optimal systems and exact solutions to the fifth-order KdV type equations, J. Math. Anal. Appl. 368 (2010) 551-558.

[15] H. LIU, Complete group classifications and symmetry reductions of the fractional fifth-order KdV types of equations, Stud. Appl. Math. 131 (2013) 317-330. 
[16] B. Lundstrom, M. Higgs, W. Spain, A. Fairhall, Fractional differentiation by neocortical pyramidal neurons, Natu. Neur. 11 (2008) 1335-1342.

[17] R. MetZler, J. KLAFTER, The restaurant at the end of the random walk: recent developments in the description of anomalous transport by fractional dynamics, J. Phys. A 37 (2004) R161-R208.

[18] C. Misbah, A. Valance, Secondary instabilities in the stabilized Kuramoto-Sivashinsky equation, Phys. Rev. E 49 (1994) 166-183.

[19] B. A. Kupershmidt, A super Korteweg-de Vries equation: An integrable system, Phys. Lett. A 102 (5-6) (1984) 213-215.

[20] Y. KuRAmoto, T. TsuZUKI, Persistent propagation of concentration waves in dissipative media far from thermal equilibrium, Progr. Theoret. Phys. 55 (1976) 356-369.

[21] P. J. Olver, Applications of Lie Groups to Differential Equations, Springer-Verlag, Heidelberg, 1986.

[22] I. Podlubny, Fractional Differential Equations, Academic Press, San Diego, CA, 1999.

[23] Y. A. Rossikhin, M. V. SHitikova, Application of fractional derivatives to the analysis of damped vibrations of viscoelastic single mass systems, Acta Mech. 120 (1997) 109-125.

[24] L. Sabatelli, S. Keating, J. Dudley, P. Richmond, Waiting time distributions in financial markets, Eur. Phys. J. B. 27 (2002) 273-275.

[25] R. SAHADEVAn, T. BAKKyARAJ, Invariant analysis of time fractional generalized Burgers and Korteweg-de Vries equations, J. Math. Anal. Appl. 393 (2012) 341-347.

[26] S. G. Samko, A. A. Kilbas, O. I. Marichev, Fractional Integrals and Derivatives: Theory and Applications, Gordon and Breach Science Publishers, Amsterdam, 1993.

[27] R. Schumer, D. A. Benson, M. M. Meerschaert, B. Baeumer, Multiscaling fractional advection-dispersion equations and their solutions, Water Reso. Res. 39 (2003) 1022-1032.

[28] R. Schumer, D. A. Benson, M. M. Meerschaert, S. W. Wheatcraft, Eulerian derivation of the fractional advection-dispersion equation, J. Cont. Hydr. 48 (2001) 69-88.

[29] G. SIVASHINSKY, Nonlinear analysis of hydrodynamic instability in laminar flames I. Derivation of basic equations, Acta Astron. 4 (1977) 1177-1206.

[30] G. WANG, X. LiU, Y. ZHANG, Lie symmetry analysis to the time fractional generalized fifth-order KdV equation, Commun. Nonlinear Sci. Numer. Simulat. 18 (2013) 2321-2326.

[31] P. Winternitz, Lie Groups and Solutions of Nonlinear Partial Differential Equations, in: Lecture Notes in Physics, CRM-1841, Canada, 1993. 